in Pharmacology' differs from its predecessor in several ways. With the geometrical progression of new knowledge in so many fields, the editors have wisely abandoned the attempt to cover everything themselves and have invited several experts to contribute in their own subjects. The fact that four of these are clinicians is, as the editors point out, an indication of present trends in research. Another important change is in format. The new edition, perhaps due to recent advances in printing, is much more attractively produced than its predecessor.

The range of subjects considered is wide and it is difficult to think of any significant omissions. There are four chapters devoted to the currently interesting and related subjects of pharmacologically active substances in the C.N.S., psychotropic drugs, catechol amines and 5-hydroxytryptamine, including a section on the clinical use of psychotropic drugs by C. M. B. Pare. M. Schachter deals with the slightly elusive subject of pharmacologically active polypeptides. W. J. H. Butterfield and R. F. Mahler discuss carbohydrate metabolism in diabetes, insulin and the oral hypoglycremic agents and L. G. Goodwin compares new and old drugs in the treatment of tropical diseases and parasitic infestations. Perhaps the best chapter is contributed by M. D. Milne, who not only discusses diuretic agents, but also gives a clear and concise account of current theories of renal physiology, with the mode of action of the drugs explained, as far as possible, in the light of these theories. Other subjects covered include steroid drugs, chemotherapeutic agents (including the newest penicillins), hypotensive agents and miscellaneous new drugs.

This new edition is an excellent book and can be thoroughly recommended, not only to pharmacologists, but to any physician interested in the pharmacological and physiological background to drug therapy.

\section{Surgeon at the Bedside}

StePhen Power, M.D., M.S., F.R.C.s. Pp. vii +162 , illustrated. London: William Heinemann Medical Books. 1962. $17 s .6 d$.

This little book gives advice on practical surgical diagnosis. It is concerned with the methodical approach to clinical surgery and does not attempt to be a treatise of differential diagnosis. The importance of detailed history-taking is rightly stressed, and tips are given on how to obtain essential history rapidly and tactfully. The chapters on the history, the evaluation of physical signs, and the uses and limitations of radiology and endoscopy are excellent guides backed by the author's long experience in abdominal surgery and urology. The cautions as to when history, physical signs, and investigations may actually mislead in diagnosis are especially useful; such situations occur not uncommonly and it is right that students should be aware of these difficulties from the start. The observations on observer error are welcome and enlightening.

Some statements made might well be challenged, for example: "Vomiting seldom occurs with other than abdominal pain'; 'A catheter should be used in the female' (for obtaining urine specimens); 'A red cell count is almost as necessary as a hæmoglobin reading '. The few 'humorous' illustrations are either irrelevent or tasteless and would have been better omitted. Despite these minor reservations this is a concise and readable book which contains much common-sense and wisdom. It could be read in a short time and with profit by senior students and house surgeons.

\section{A History of American Pathology}

Esmond R. Long, M.D., PH.D. Pp. xiv + 460, illustrated. Springfield, Illinois: Charles $C$ Thomas. 1962. \$12.50.

Those who read with delight Long's 'A History of. Pathology' (1928), will be disappointed that that masterly performance has not been repeated in the $\stackrel{D}{\rightarrow}$ present volume, which is essentially a vast chronology $\bar{C}$ of dates of birth, professorial appointment and death, $\frac{C}{O}$ of all American and Canadian Pathologists, with a $\overline{\bar{c}}$ broad interpretation of the title in the earlier less $\vec{\partial}$

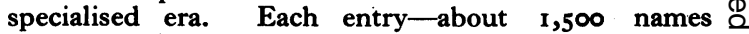
occur-receives a notice according to importance, Welch alone being distinguished by a chapter woven o around his professional life, but most of the book is $\overrightarrow{0}$ patterned on the Book of Chronicles rather than Aubrey's Brief Lives. The backcloth to the names $\vec{\omega}$ consists of the institutions they graced, the details of the evolving administration, the founding of licensing $\bar{C}$ bodies, medical schools, societies and journals, and we are reminded that the United States is a federal union, with regional variation in the timing and pattern of $\underset{\mathcal{W}}{W}$ development.

The truth is, that in an age of rapid communication and easy travel-the period covered by three-quarters of the book down to the present day-regional differences in the theory, practice and teaching of such broad disciplines as pathology commands, become of quite secondary importance, and of local, or at most national interest. Clearly for historical, geographical and economic reasons, some American contributions to the general body of pathological knowledge are unique. An account of such achievements, with characte studies, incidents, and judicious commentaries and opinions blended into the narrative would form 9 fairly distinctive history of American pathology, to be assimilated by the general reader. Nowhere in the present text do we have any sense of intimacy with the American scene: there is no lingering, no discursive aside. It is the dust of the ground waiting for the breath of life to be breathed into it.

\section{The Exocrine Pancreas, Normal and Abnormal} Functions

Ciba Foundation Symposium. Editors: A. V. S. De Reuck, and Margaret P. Cameron. Pp. xii + 390. London: J. \& A. Churchill. 1962. 55s.

A small conference of twenty-eight distinguished investigators has a more refined and creative atmosphere than is possible from large international meetings. This symposium is the first that the Ciba Foundation has devoted to any part of the alimentary tract, and may it be the first of others. The book, well produced, is a record of deliberations covering three days, under the chairmanship of Professor Sheila Sherlock. It has many illustrations such as photographs from the electron microscope, electrophoretic strips, graphs and histograms, is properly documented with references, and fully indexed.

The inelegant title may not convey to every reader its scope. Exocrine, he may correctly conclude, is the opposite to endocrine and refers to the external secretion This indeed is covered fully; and a great deal more. even though insulin and the Zollinger-Ellison Syndrome are excluded. The first subject is the pancreatic cell, its ultrastructure and histochemistry, and the physiology of zymogen granules and other sub-cellular particles which may be precursors of the enzyme of pancreatic $\stackrel{\mathscr{C}}{+}$ juice. Sections concerning the nature and physiological control of pancreatic secretion lead on naturally to the

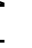

